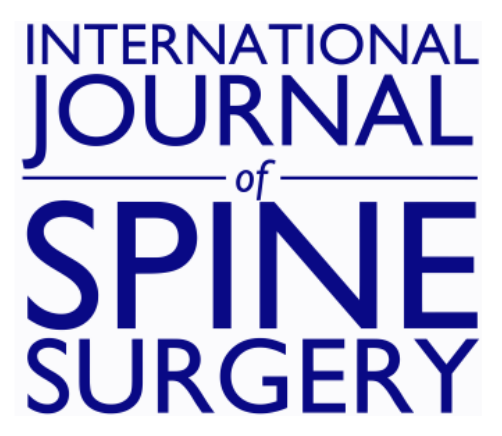

\title{
The Clinical Impact of Image Guidance and Robotics in Spinal Surgery: A Review of Safety, Accuracy, Efficiency, and Complication Reduction
}

David H. Campbell, Donnell McDonald, Kasra Araghi, Tala Araghi, Norman Chutkan and Ali Araghi

Int J Spine Surg 2021, 15 (s2) S10-S20

doi: https://doi.org/10.14444/8136

http://ijssurgery.com/content/15/s2/S10

This information is current as of April 26, 2023.

Email Alerts Receive free email-alerts when new articles cite this article. Sign up at: http://ijssurgery.com/alerts 


\title{
The Clinical Impact of Image Guidance and Robotics in Spinal Surgery: A Review of Safety, Accuracy, Efficiency, and Complication Reduction
}

\author{
DAVID H. CAMPBELL, MD,${ }^{1}$ DONNELL MCDONALD, MD, ${ }^{1}$ KASRA ARAGHI ${ }^{2}$ TALA ARAGHI, ${ }^{2}$ \\ NORMAN CHUTKAN, MD, ${ }^{1,3}$ ALI ARAGHI, DO ${ }^{3}$ \\ ${ }^{I}$ Department of Orthopaedic Surgery, University of Arizona College of Medicine, Phoenix, Arizona,${ }^{2}$ Arizona State University, Tempe, Arizona, ${ }^{3}$ The CORE \\ Institute, Phoenix, Arizona
}

\begin{abstract}
Image guidance (IG) and robotic-assisted (RA) surgery are modern technological advancements that have provided novel ways to perform precise and accurate spinal surgery. These innovations supply real-time, three-dimensional imaging information to aid in instrumentation, decompression, and implant placement. Although nothing can replace the knowledge and expertise of an experienced spine surgeon, these platforms do have the potential to supplement the individual surgeon's capabilities. Specific advantages include more precise pedicle screw placement, minimally invasive surgery with less reliance on intraoperative fluoroscopy, and lower radiation exposure to the surgeon and staff. As these technologies have become more widely adopted over the years, novel uses such as tumor resection have been explored. Disadvantages include the cost of implementing IG and robotics platforms, the initial learning curve for both the surgeon and the staff, and increased patient radiation exposure in scoliosis surgery. Also, given the relatively recent transition of many procedures from inpatient settings to ambulatory surgery centers, access to current devices may be cost prohibitive and not as readily available at some centers. Regarding patient-related outcomes, much further research is warranted. The short-term benefits of minimally invasive surgery often bolster the perioperative and early postoperative outcomes in many retrospective studies on IG and RA surgery. Randomized controlled trials limiting such confounding factors are warranted to definitively show potential independent improvements in patient-related outcomes specifically attributable to IG and RA alone. Nonetheless, irrespective of these current unknowns, it is clear that these technologies have changed the field and the practice of spine surgery. Surgeons should be familiar with the potential benefits and tradeoffs of these platforms when considering adopting IG and robotics in their practices.
\end{abstract}

Special Issue Article

\section{INTRODUCTION}

During the last several decades, image guidance (IG) and robotic-assisted (RA) systems have become increasingly used for the performance of safe and effective spinal surgery. Both are associated with an initial investment and learning curve but have the potential to increase the accuracy of instrumentation, potentiate more efficient and faster surgery, utilize less invasive surgical approaches, and decrease radiation exposure. ${ }^{1}$

In the past, spinal surgeons relied solely on freehand and fluoroscopically guided techniques, using orthogonal imaging and anatomic exposure to guide pedicle screw insertion and neural decompression. While navigation and robotics cannot supplant the anatomic understanding and feel of an experienced spine surgeon's hands, they do have the potential to augment the surgeon to achieve better outcomes and perform surgery in novel, possibly better ways. These technologies can be especially advantageous in situations where the normal anatomy is not present, such as transitional lumbosacral vertebrae, lytic spondylolisthesis, and high-riding vertebral arteries at $\mathrm{C} 2$.

Image-guided navigation systems combine intraoperative imaging with computerized referenced navigation systems to provide real-time stereotactic imaging, allowing for dynamic repositioning and feedback of navigated instruments. Options for imaging include standard 2-dimensional (2D) fluoroscopy, fluoroscopy reformatted into $3 \mathrm{D}$, and computed tomography (CT). In most platforms, an infrared registration device is affixed to the patient, such as into the iliac crest or clamped to a spinous process. Following this, intraoperative imaging is performed to coregister the patient's 
imaging to the device, providing a stable reference point for the navigated instruments, reducing or eliminating the need for intraoperative fluoroscopy. Alternatively, some platforms have a trackerless option with manual registration of bone surfaces in relation to the position of the IG system. Some have also utilized electromagnetic sensors which do not require line-of-sight between the instruments and array. The predominant application of IG is the planning and placement of pedicle screws, but most systems include a variety of instrumentation such as high-speed burrs, drills, taps, and rongeurs.

Currently, a wide variety of IG navigation systems are available for use. Each imaging system is paired with a proprietary computer navigation software platform. Most have certain defining features. The O-arm with StealthStation S8 (Medtronic, Minneapolis, Minnesota) uses a fluoroscopy unit on a circular track that encloses around the operative table. The software platform utilizes an algorithm that reformats the combination of $2 \mathrm{D}$ images into a $3 \mathrm{D}$ reconstruction. The end result is similar in appearance to a CT scan. The Airo iCT with Curve or VectorVision (Brainlab, Munich, Germany) is a true CT platform, and the unit itself is therefore more similar in appearance to a standard CT scanner. It features improved soft tissue resolution and a relatively robust size for imaging larger patients. The Ziehm Vision RFD 3D (Ziehm Imaging, Orlando, Florida) is a motorized, automated $\mathrm{C}$-arm that spins $180^{\circ}$ around the patient. It has the capability to take standard fluoroscopic images and provide volume-rendered, multiplanar reconstructed 3D imaging for IG.

There are currently a number of commercial robotic systems available as well. Robotics systems fall into 2 major categories. The first are supervisory-controlled systems, in which the surgeon preoperatively plans the surgery using the provided software and then supervises the robot as it autonomously performs steps in the operation. The second type is a shared-control system in which the surgeon manually controls the instruments with the robot providing feedback and fine-tuning. This latter type is the function of all currently approved spinal robotics systems. ${ }^{2}$ The Mazor SpineAssist, which was the first to receive US Food and Drug Administration approval, is currently the most published robotic system. The system uses a device that is mounted to the patient using 2 Steinman pins, allowing for shared control with 6 degrees of freedom. The most recent iteration of the Mazor robot is a result of Medtronic's acquisition of Mazor Robotic, combining the Mazor system with the existing Stealth IG navigation platform. It features what is now a universal element in the most modern systems: a fully automated robotic arm. Other systems with similar capabilities include the Excelsius GPS (Globus, Audubon, Pennsylvania), the ROSA ONE (Zimmer Biomet, Warsaw, Indiana), and the recently released Cirq (Brainlab, Munich, Germany). Planning of screw trajectories is a common feature that is available after uploading a CT into the provided software.

\section{SAFETY}

One of the foremost advantages to IG and RA platforms is the potential reduction in radiation exposure to the patient, surgeon, and operating room staff. $^{3}$ Strategies for decreasing exposure during fluoro-guided instrumentation include proper protective equipment, minimizing fluoroscopic dose and use, using a "hands-off" technique during pedicle screw instrumentation, and collimation of the x-ray beam. ${ }^{4-6}$

When compared to fluoro-guided techniques in adult lumbar spinal surgery, image-guided navigation has a significant potential to minimize exposure to the surgeon and staff. ${ }^{7}$ The patient benefit is much less certain. Image-guided minimally invasive surgery (MIS) procedures likely result in less exposure, but open procedures may result in an equivalent or higher dose secondary to the intraoperative CT. A randomized control trial by Villard et $\mathrm{al}^{8}$ comparing exposure during open posterior lumbar instrumentation to CT IG showed a nearly 10 -fold decrease in exposure to the surgeon and staff and a nonsignificant trend towards lower patient exposure. Other studies have shown higher patient exposure. ${ }^{9}$ A decrease in patient and staff exposure has been shown when comparing IG MIS lumbar surgery to a fluoro-guided technique. ${ }^{10}$ In adult MIS scoliosis correction, IG may result in a lower patient exposure. ${ }^{11}$ Similar benefits have been shown with MIS transforaminal lumbar interbody fusion (TLIF). ${ }^{12,13}$

The use of IG in long segment constructs in scoliosis surgery for radiation reduction is more controversial. Freehand techniques combined with intermittent fluoroscopy are commonly used in the treatment of pediatric idiopathic scoliosis. These more traditional techniques have been shown to 
result in a lower dose exposure to the patient than CT IG. ${ }^{14-16}$ Lower-dose protocols have been developed to mitigate this problem in IG and RA surgery. ${ }^{17,18}$

\section{ACCURACY}

Accurate pedicle screw placement is an essential component of spine surgery. Pedicle screw misplacement is fairly common, with rates reported up to as high as 40 to $50 \% .^{19-21}$ Severely misplaced placed screws more than 2-4 mm off, particularly in the inferior or medial directions, can result in complications such as dural tears, nerve root and spinal cord injury, significant bleeding, injury to visceral organs, and life-threating events. ${ }^{22}$ Fortunately, symptomatic malposition requiring revision is not a frequent occurrence, even with traditional methods, and in one large series only $0.8 \%$ of patients required a return to the operating room to correct significantly malpositioned screws placed with the freehand technique. Most of the $9.0 \%$ of screws that were malpositioned involved a pedicle wall breach, lateral being more common than medial and thoracic more frequent than lumbar. ${ }^{23}$ Despite the fortunate fact that slight malposition is often clinically silent, maximally accurate pedicle screw insertion with excellent purchase is desired in all cases because even minor malposition can sometimes result in complications.

Multiple trials have investigated whether IG navigation improves accuracy versus freehand technique and 2D fluoroscopy. ${ }^{24}$ A number of single studies have consistently reported a 95\% accuracy rate of CT IG-navigated cohorts compared with conventional freehand and fluoro-guided methods which were roughly $10 \%$ less accurate. ${ }^{24-27}$ One study also reported less need for screw repositioning intraoperatively compared to freehand, and several studies have reported pedicle screw replacement around 5\% less frequently in IG groups compared with other methods. ${ }^{17,27,28}$ The reported differences in large-scale meta-analyses have been less dramatic. A 2019 comprehensive systematic review and metaanalysis pooling more than 50000 screws demonstrated that CT IG navigation was $95.5 \%$ accurate versus $93.1 \%$ for fluoro-guided and $91.5 \%$ for freehand. ${ }^{29}$ Interestingly, the revision rate for fluoro-guided was higher than freehand and IG, which were similar. Another meta-analysis reported that using IG resulted in a reduction of pedicle perforations measuring more than $2 \mathrm{~mm}$ compared to the freehand technique. ${ }^{30}$ It should be noted that the authors noted heterogeneity in these results. Subgroup analysis demonstrated regional differences that suggested variability in surgeon skill and potentially more challenging patient anatomy due to the ethnic groups being treated. The findings also suggested that less experienced surgeons who were not yet proficient with traditional techniques were more accurate with the IG systems. ${ }^{31}$

Regarding pedicle screw placement with robotic systems, a recent meta-analysis of 9 randomized control trials concluded that RA surgery resulted in more accurate pedicle screw placement than freehand surgery. However, surgery times were longer in the RA cases and postoperative length of stay along with patient outcome scores showed no significant difference between the groups. ${ }^{32} \mathrm{Kim}$ et $\mathrm{al}^{33}$ reported better convergence orientation for pedicle screws along with fewer facet joint violations with the robot-assisted surgeries.

Another important consideration during pedicle screw instrumentation of the lumbosacral spine is preservation of the proximal facet joint at the cranial end of the construct. Violation may predispose to higher rates of adjacent segment disease. ${ }^{34-36}$ Lower rates of cranial facet joint violation have been reported using a percutaneous IG technique compared with an open technique. ${ }^{37,38}$ Similar improvements have been shown in RA surgery for both standard pedicle screw instrumentation and with screws in the cortical bone trajectory. ${ }^{39-41}$

Although thoracic and lumbar pedicle screw instrumentation comprise the majority of guided instrumentation, IG and robotics have also been applied in the cervical spine. Zhang et $\mathrm{al}^{42}$ reported $96.5 \%$ accuracy in 144 posterior cervical pedicle screws placed with CT IG. There were 5 pedicle breaches but no major complications in the short term. Theologis and Burch $^{43}$ reported 99\% safely placed screws, with 1 medial breach causing a C5 root palsy. A recent well-constructed randomized controlled trial by Fan et $\mathrm{al}^{44}$ reported excellent results with robot-assisted cervical instrumentation. Other authors have cautioned that even with the advantage of CT-based IG, the risk of pedicle perforation in the middle cervical spine is high. ${ }^{4-47}$ Other cervical pathology treated using IG navigation includes posterior $\mathrm{C} 1-\mathrm{C} 2$ fusion for atlantoaxial instability, C1-C2 fixation for Hangman's fracture, odontoid screw fixation, os odontoideum 
fixed with Magerl and Harms techniques, and occiput-C2 fusion. ${ }^{48-53}$

Image-guided and RA techniques have also been explored for sacral and iliac fixation. Most authors report good results placing S2 alar iliac screws using both IG and RA. ${ }^{54-58}$ Lumbosacral fixation has also been described. ${ }^{59}$ Santos et $\mathrm{al}^{60}$ demonstrated in a cadaver study that IG may improve the insertional torque of iliac screws by achieving a longer trajectory using 3D IG.

\section{EFFICIENCY}

Another critical factor in adopting new technology is the surgeon and staff overcoming the learning curve and becoming efficient with the use of the platform. The literature suggests that IG systems are relatively easily learned and integrated for simpler techniques, and efficiency increases over time with regard to workflow and screw placement time. ${ }^{61,62}$ Ryang et $\mathrm{al}^{62}$ reported their experience adopting IG navigation in their hospital. The overall workflow, which involves surgeons and operating room staff familiar with the system and 3D acquisition, improves rapidly at the outset and then less dramatically during the 12 months following implementation of the system. Routine use of the technology during most cases normalizes utilization and may improve this efficiency over time.

In terms of pedicle screw instrumentation, there does seem to be a benefit with experienced operators. In a study examining thoracic pedicle screw accuracy with navigated and fluoro-guided techniques, the average insertion time per pedicle screw was noted to be more than 2 minutes greater in the fluoro-guided group. ${ }^{26}$ Other studies have similarly noted that navigation results in either an equivalent or reduced operative time for surgeons practiced in IG techniques. ${ }^{10,11,63-65}$

For residents and fellows training on a robotics platform, Urakov et $\mathrm{al}^{66}$ noted there was a nonsignificant trend towards more efficiency with experience, but even junior residents were able to perform instrumentation in a reasonable time. It has been reported that competent supervision should be provided for the first 25 to 30 cases, as there is an increased incidence of pedicle wall breach and screw revision in this range. ${ }^{67,68}$

Regarding navigated interbody instrumentation, $\mathrm{Xu}$ et $\mathrm{al}^{69}$ published their experience with incorporating IG into their TLIF technique. They noted that operative time had reached an efficient level after 25 cases. It should be acknowledged that the surgeon was already practiced at IG spinal surgery and was also performing other navigated cases during the study period.

\section{COMPLICATIONS REDUCTION}

Improving patient outcomes and reducing the rate of complications is a constant consideration in spinal surgery, particularly when assessing the cost and learning curve of adopting a new platform and workflow. The comparative results of IG and RA have been encouraging but mixed. Most studies have not shown any dramatic differences. Khanna et $\mathrm{al}^{65}$ compared single-level MIS TLIF using fluoro or CT IG and found that intraoperative blood loss was actually higher in the IG group. They found no difference in all other perioperative and short-term clinical outcomes, such as surgical time, complications, and hospital length of stay. ${ }^{70}$ In a wellconstructed retrospective cohort comparing IG navigation to fluoroscopy, Vaishnav et al ${ }^{10}$ reported similar clinical outcomes, operative variables, and radiation exposure when performing microdiscectomy, laminectomy, and MIS TLIF. In a randomized study by Park et $\mathrm{al}^{71}$ comparing RA to conventional pedicle screw instrumentation for posterior interbody fusion, there were no differences in adjacent segment disease or clinical outcomes at 2 years.

In contrast, some studies have shown some promising results. One study of 413 cases using RA guidance for pedicle screw placement noted a lower rate of complications than previously published series using other techniques for percutaneous screw placement. $^{72}$

A common comparison is between conventional open technique and MIS using IG or robotics. There are improvements in perioperative variables and short-term outcomes, but it is difficult to determine whether these benefits are secondary to the technology or the MIS approach. Compared to open TLIF, Tian et $\mathrm{al}^{73}$ noted that minimally invasive TLIF using IG did result in longer operative times but less blood loss, fewer transfusions, and less postoperative drainage than open TLIF. They noted that their extended operative time may have been related to a learning curve. Similar to findings from other MIS papers, early clinical markers, such as postoperative VAS back pain and hospital length of stay, were better, but at 2 years clinical outcomes were no different than 
open surgery. In comparing IG instrumentation for posterior fusion to freehand and fluoro-guided techniques, Xiao et $\mathrm{al}^{74}$ noted a more than $50 \%$ reduction in reoperation in the navigated group, specifically with regard to hardware failure and screw misplacement. Another study specifically comparing freehand technique to RA for both pedicle instrumentation and PLIF cage insertion reported no difference in clinical outcomes or fusion at 1 year, although the authors did note that the cases performed with freehand PLIF were more likely to have decreased disc height at the proximal adjacent segment. ${ }^{75}$ Hyun et $\mathrm{a}^{76}$ compared a cohort of 60 patients undergoing RA MIS or fluoro-guided open surgery for 1- or 2-level posterior fusion. They noted a decreased length of stay and reduced radiation exposure in the RA group. Jiang et $\mathrm{al}^{77}$ matched a cohort of patients undergoing RA MIS or freehand open 1- or 2-level lumbar fusion surgery, noting less intraoperative blood loss and shorter hospital stay in the RA group. Again, it is unclear if the differences noted in these studies were primarily due to the use of IG and RA or the differences in short-term outcomes between MIS and open techniques. Overall, further randomized, controlled studies with the elimination of confounding factors such as differences in surgical approach would be highly benefitial. ${ }^{78}$

\section{DISCUSSION}

Accuracy becomes even more difficult to attain when there is abnormal anatomy where the structures are more complex. Some examples include revision fusion surgery and surgery on the upper cervical spine. In the case of sacroiliac joint fusion, accurately targeting the ventral and articular portion of the joint may increase the chance of getting a solid union. One of the advantages of RA/ IG systems is that they allow perioperative and intraoperative adjustments, respectively. One can optimize screw trajectories to avoid dangerous territory, such as a high-riding vertebral artery foramen in placement of $\mathrm{C} 2$ screws and when instrumenting dysplastic pedicles. This same capacity for fine-tuning and adjustment allows for optimizing the width and length of pedicle screws. This maximizes bony purchase while staying safe, increasing pedicle fill, and getting bicortical purchase in challenging areas such as the occiput and sacrum. Anecdotally, the senior author's size of pelvic fixation screws has increased with the assistance of such technologies. As our population ages, this opportunity for more rigid and robust fixation becomes more and more important.

Figure 1 depicts the intraoperative assessment for optimizing an upper thoracic pedicle screw. Shown here is the decision to downsize the screw length from 45 to $40 \mathrm{~mm}$. This technique allows for the safe maximization of screw length while avoiding dangerous breaches. Different screw insertion techniques can be chosen based on visualization of the costotransverse junction and the size of the pedicle, allowing the surgeon to make a better decision on the optimal choice of the trajectory for an outside-in trajectory versus a transpedicular approach. The width and length of the screw can then be adjusted to increase purchase as discussed above. Screw entry position can also be optimized both for purposes of aligning screw heads for rod placement, or differential positioning to maximize the correction with rod de-rotation techniques. In addition, one can see the exact position of the anterior vascular anatomy with respect to the intended instrumentation tract.

In posterior lumbar cases, the proximal facet is easily visualized using IG as seen in Figure 2. Avoidance of proximal facet violation is therefore much more easily accomplished. In fact, an even further lateral starting point would be obtainable using navigation and would likely be more ideal. Figure 3 shows the exact angle for preventing cephalad/caudal facet violations in the posterior cervical spine. In this case, the screw length was first projected to be $16 \mathrm{~mm}$. The saved trajectory, which is outlined in pink, shows the adjustment to a 14$\mathrm{mm}$ screw to avoid a ventral cortical breach.

Challenges in sacroiliac joint instrumentation include dysplastic anatomy and bowel gas shadows that hinder identification of the anatomy required for safe instrumentation. This is especially true in cases of older patients with osteoporotic bone in whom strong fixation is essential. Figure 4 depicts an example of the different views available with IG, showing clear delineation of the anatomic structures. The top left image confirms that the trajectory is ventral enough to access the articular area of the joint. The top right shows the location of the iliac cortical density above which runs the L5 root. This enables the surgeon again to maximize the length of the instrumentation and access the optimal bone density within zone II while stopping short of the iliac cortical density. At times, the amount of safe bony real estate can make it 


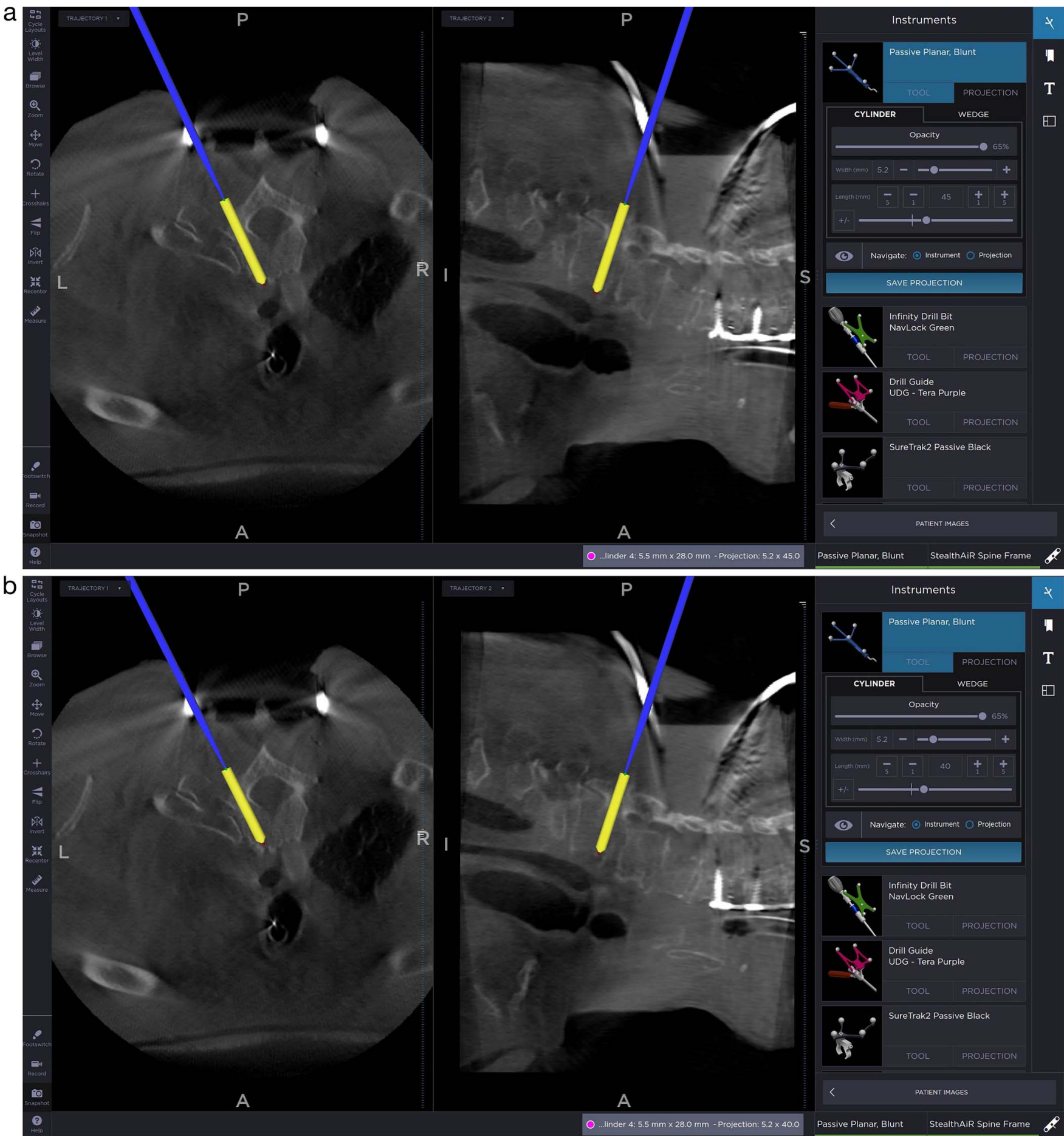

Figure 1. Evaluation of the upper thoracic costotransverse joint for assessment of extrapedicular versus transpedicular approaches. Also shown is adjustment of the pedicle screw length from 45 to $40 \mathrm{~mm}$ to avoid ventral breach.

difficult to accept multiple implants, especially in cases of smaller patients. The bottom left picture allows the surgeon to plan for more than one implant while staying within the intra-articular portion of the joint. The coronal cuts seen in the bottom right image can be used not only for implant planning but also for visualization of implant positioning with respect to the sacral foramina.

These applications of the advanced IG systems available today provide concrete examples of the advantageous and obtainable improvements in accuracy and safety as quoted in our literature review. 


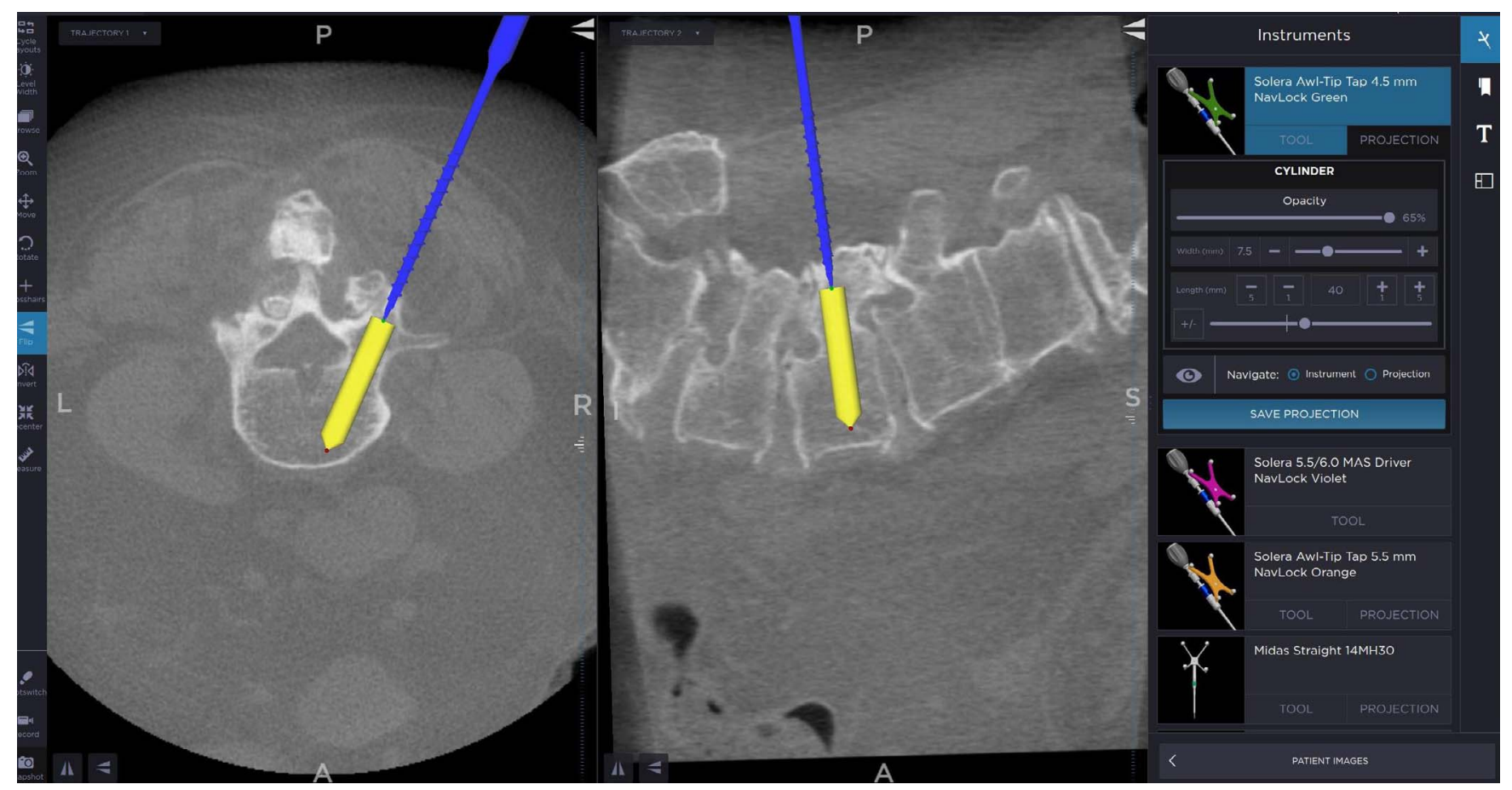

Figure 2. Optimization of pedicle screw trajectory for better pedicle fill and length. This also allows visualization of the facet joint for the avoidance of proximal facet violation and adjacent segment disease.

\section{CONCLUSION}

Image guidance and robotics are powerful tools for assisting surgeons in performing safe and effective spinal surgery. Although no technology can replace the clinical knowledge, anatomic understanding, and technical skill of an experienced spinal surgeon, these systems have the potential to improve accuracy of instrumentation, reduce surgeon and staff radiation exposure, and augment workflow during surgery. Barriers to implementation are cost and the learning curve of the system for the staff and surgeon, but in the right scenario both are feasible. Future developments, which include using MRI data to map out nerves for lateral psoas-based approaches and burr-based laminectomy aided by

Figure 3. Image-guided trajectory for lateral mass fixation in the posterior cervical spine with avoidance of the facet joints. Also shown is adjustment of the screw length from 16 to 14 $\mathrm{mm}$ to avoid a ventral breach. An all in-bone trajectory avoids injury to the exiting nerve root and vertebral artery.

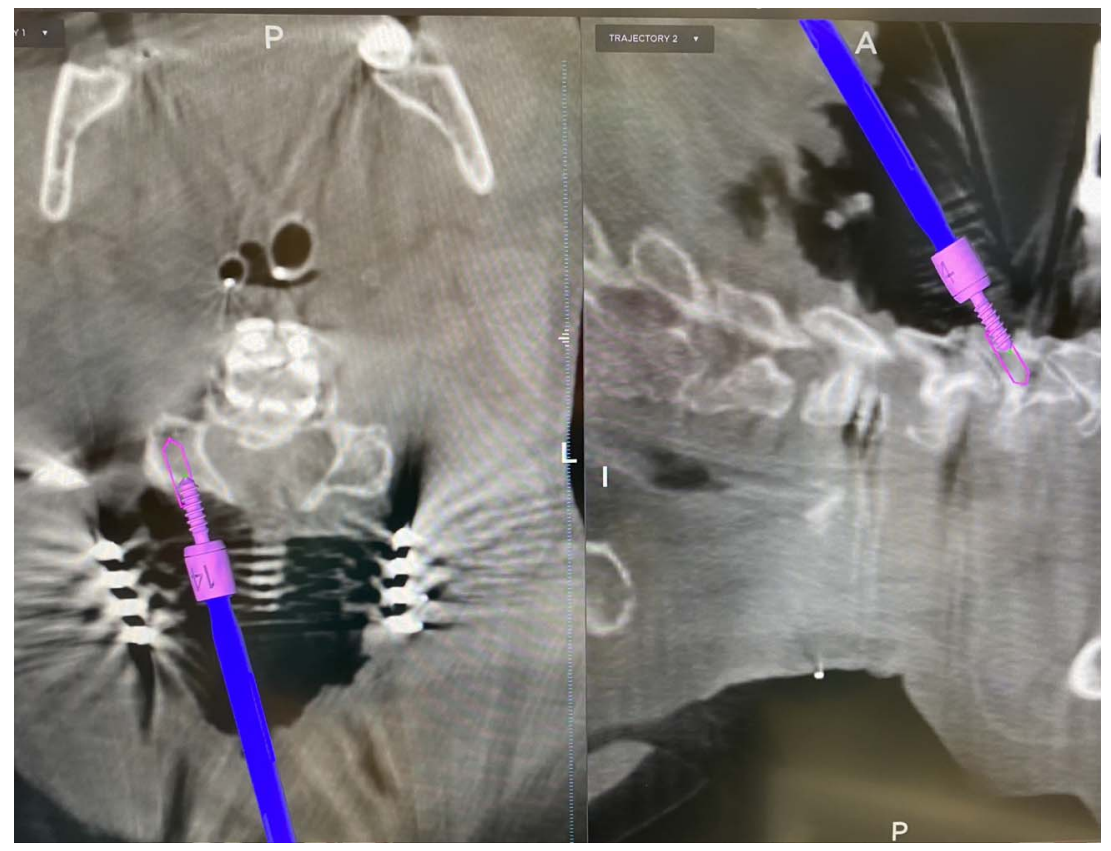




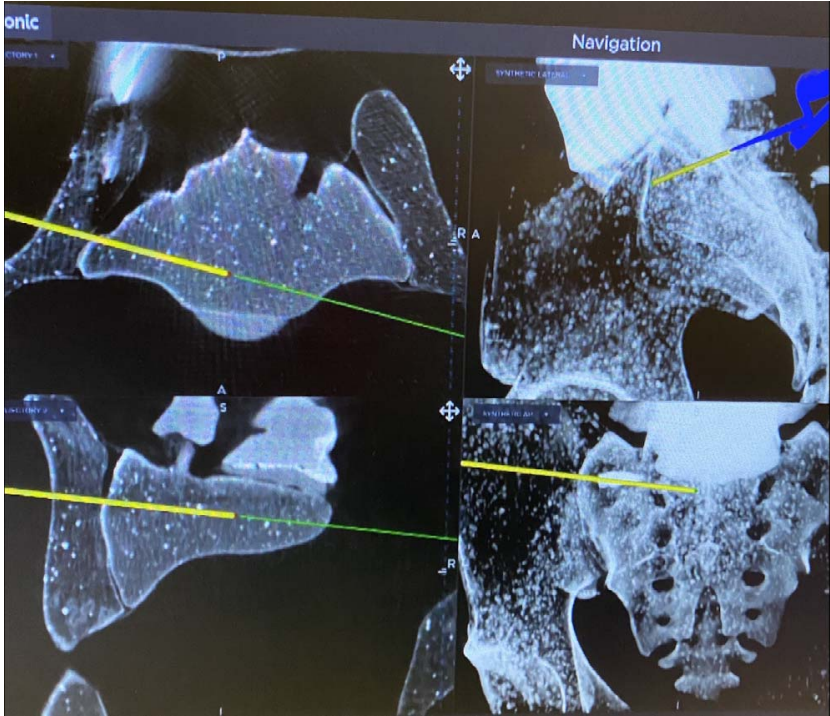

Figure 4. Sacroiliac joint fixation using image guidance. The top left image confirms that the trajectory is ventral enough to access the articular area of the joint. The top right shows the location of the iliac cortical density above which runs the L5 root. The bottom left picture allows the surgeon to plan for more than 1 implant while staying within the intra-articular portion of the joint. The coronal cuts seen in the bottom right can be used not only for implant planning but also for visualization of implant positioning with respect to the sacral foramina.

robot-guided haptic feedback, will continue to expand the utility and usefulness of these technologies. The creation of so called "no-fly" zones can certainly assist with revision and or tumor decompressions while maintaining safety. Large wellconstructed randomized trials will be required to definitively establish independent improvements in patient-specific variables, such as intraoperative blood loss, complications, and postoperative clinical outcomes.

\section{REFERENCES}

1. Tian NF, Huang QS, Zhou P, et al. Pedicle screw insertion accuracy with different assisted methods: a systematic review and meta-analysis of comparative studies. Eur Spine $J$. 2011;20(6):846-859.

2. Nathoo N, Çavuşoğlu MC, Vogelbaum MA, Barnett GH. In touch with robotics: neurosurgery for the future. Neurosurgery. 2005;56(3):421-433.

3. Mehta JS, Hodgson K, Yiping L, et al. Radiation exposure during the treatment of spinal deformities. Bone Joint J. 2021;103B(4):1-7.

4. Srinivasan D, Than KD, Wang AC, et al. Radiation safety and spine surgery: systematic review of exposure limits and methods to minimize radiation exposure. World Neurosurg. 2014;82(6):1337-1343.

5. Mroz TE, Yamashita T, Davros WJ, Lieberman IH. Radiation exposure to the surgeon and the patient during kyphoplasty. J Spinal Disord Tech. 2008;21(2):96-100.

6. Mroz TE, Abdullah KG, Steinmetz MP, Klineberg EO, Lieberman IH. Radiation exposure to the surgeon during percutaneous pedicle screw placement. J Spinal Disord Tech. 2011;24(4):264-267.

7. Nottmeier EW, Bowman C, Nelson KL. Surgeon radiation exposure in cone beam computed tomography-based, image-guided spinal surgery. Int J Med Robot Comput Assist Surg. 2012;8(2):196-200.

8. Villard J, Ryang YM, Demetriades AK, et al. Radiation exposure to the surgeon and the patient during posterior lumbar spinal instrumentation: a prospective randomized comparison of navigated versus non-navigated freehand techniques. Spine. 2014;39(13):1004-1009.

9. Costa F, Tosi G, Attuati L, et al. Radiation exposure in spine surgery using an image-guided system based on intraoperative cone-beam computed tomography: analysis of 107 consecutive cases. J Neurosurg Spine. 2016;25(5):654-659.

10. Vaishnav AS, Merrill RK, Sandhu H, et al. A review of techniques, time demand, radiation exposure, and outcomes of skin-anchored intraoperative 3D navigation in minimally invasive lumbar spinal surgery. Spine. 2020;45(8):E465-E476.

11. Tajsic T, Patel K, Farmer R, Mannion RJ, Trivedi RA. Spinal navigation for minimally invasive thoracic and lumbosacral spine fixation: implications for radiation exposure, operative time, and accuracy of pedicle screw placement. Eur Spine J. 2018;27(8):1918-1924.

12. Hubbe U, Sircar R, Scheiwe C, et al. Surgeon, staff, and patient radiation exposure in minimally invasive transforaminal lumbar interbody fusion: impact of 3D fluoroscopy-based navigation partially replacing conventional fluoroscopy: study protocol for a randomized controlled trial. Trials. 2015;16:142. doi:10.1186/s13063-015-0690-5

13. Kim CW, Lee YP, Taylor W, Oygar A, Kim WK. Use of navigation-assisted fluoroscopy to decrease radiation exposure during minimally invasive spine surgery. Spine J. 2008;8(4):584590.

14. Urbanski W, Jurasz W, Wolanczyk M, et al. Increased radiation but no benefits in pedicle screw accuracy with navigation versus a freehand technique in scoliosis surgery. Clin Orthop. 2018;476(5):1020-1027.

15. O'Donnell C, Maertens A, Bompadre V, Wagner TA, Krengel W 3rd. Comparative radiation exposure using standard fluoroscopy versus cone-beam computed tomography for posterior instrumented fusion in adolescent idiopathic scoliosis. Spine. 2014;39(14):E850-E855.

16. Dabaghi Richerand A, Christodoulou E, Li Y, Caird MS, Jong N, Farley FA. Comparison of effective dose of radiation during pedicle screw placement using intraoperative computed tomography navigation versus fluoroscopy in children with spinal deformities. J Pediatr Orthop. 2016;36(5):530533.

17. Pireau N, Cordemans V, Banse X, Irda N, Lichtherte S, Kaminski L. Radiation dose reduction in thoracic and lumbar spine instrumentation using navigation based on an intraoperative cone beam CT imaging system: a prospective randomized clinical trial. Eur Spine J. 2017;26(11):2818-2827.

18. Sensakovic WF, O'Dell MC, Agha A, Woo R, Varich L. CT radiation dose reduction in robot-assisted pediatric spinal surgery. Spine. 2017;42(7):E417-E424.

19. Gelalis ID, Paschos NK, Pakos EE, et al. Accuracy of pedicle screw placement: a systematic review of prospective in vivo studies comparing free hand, fluoroscopy guidance and navigation techniques. Eur Spine J. 2012;21(2):247-255.

20. Amato V, Giannachi L, Irace C, Corona C. Accuracy of 
pedicle screw placement in the lumbosacral spine using conventional technique: computed tomography postoperative assessment in 102 consecutive patients. J Neurosurg Spine. 2010;12(3):306-313.

21. Bledsoe JM, Fenton D, Fogelson JL, Nottmeier EW. Accuracy of upper thoracic pedicle screw placement using three-dimensional image guidance. Spine J. 2009;9(10):817-821.

22. Aoude AA, Fortin M, Figueiredo R, Jarzem P, Ouellet J, Weber MH. Methods to determine pedicle screw placement accuracy in spine surgery: a systematic review. Eur Spine J. 2015;24(5):990-1004.

23. Parker SL, McGirt MJ, Farber SH, et al. Accuracy of free-hand pedicle screws in the thoracic and lumbar spine: analysis of 6816 consecutive screws. Neurosurgery. 2011;68(1):170-178; discussion 178.

24. Yu X, Xu L, Bi L. Spinal navigation with intra-operative 3D-imaging modality in lumbar pedicle screw fixation [in Chinese]. Zhonghua Yi Xue Za Zhi. 2008;88(27):1905-1908.

25. Wu H, Gao Z, Wang J, Li Y, Xia P, Jiang R. Pedicle screw placement in the thoracic spine: a randomized comparison study of computer-assisted navigation and conventional techniques. Chin J Traumatol. 2010;13(4):201-205.

26. Rajasekaran S, Vidyadhara S, Ramesh P, Shetty AP. Randomized clinical study to compare the accuracy of navigated and non-navigated thoracic pedicle screws in deformity correction surgeries. Spine. 2007;32(2):E56-E64.

27. Laine T, Lund T, Ylikoski M, Lohikoski J, Schlenzka D. Accuracy of pedicle screw insertion with and without computer assistance: a randomised controlled clinical study in 100 consecutive patients. Eur Spine J. 2000;9(3):235-240.

28. Scheufler KM, Franke J, Eckardt A, Dohmen H. Accuracy of image-guided pedicle screw placement using intraoperative computed tomography-based navigation with automated referencing, part II: thoracolumbar spine. Neurosurgery. 2011;69(6):1307-1316.

29. Perdomo-Pantoja A, Ishida W, Zygourakis C, et al. Accuracy of current techniques for placement of pedicle screws in the spine: a comprehensive systematic review and metaanalysis of 51, 161 screws. World Neurosurg. 2019;126:664678.e3.

30. Tian W, Zeng C, An Y, Wang C, Liu Y, Li J. Accuracy and postoperative assessment of pedicle screw placement during scoliosis surgery with computer-assisted navigation: a metaanalysis. Int J Med Robot Comput Assist Surg. 2017;13(1). doi: $10.1002 /$ rcs. 1732

31. Soh TLT, Kho KC, Lim ZK, Tandon AA, KaliyaPerumal AK, Oh JYL. Morphological parameters of the thoracic pedicle in an asian population: a magnetic resonance imaging-based study of 3324 pedicles. Global Spine J. 2021;11(4):437-441.

32. Li HM, Zhang RJ, Shen CL. Accuracy of pedicle screw placement and clinical outcomes of robot-assisted technique versus conventional freehand technique in spine surgery from nine randomized controlled trials: a meta-analysis. Spine. 2020;45(2):E111-E119.

33. Kim HJ, Jung WI, Chang BS, Lee CK, Kang KT, Yeom JS. A prospective, randomized, controlled trial of robot-assisted vs freehand pedicle screw fixation in spine surgery. Int $\mathrm{J} \mathrm{Med}$ Robot Comput Assist Surg. 2017;13(3). doi:10.1002/rcs.1779

34. To C, Cheung P, Ng W, Mok W. Comparison of facet joint violation in lumbar posterior spinal instrumentation using different techniques including cortical bone trajectory. J Orthop Trauma Rehabil. 2020;27(1):57-62.

35. Aota Y, Kumano K, Hirabayashi S. Postfusion instability at the adjacent segments after rigid pedicle screw fixation for degenerative lumbar spinal disorders. J Spinal Disord. 1995;8(6):464-473.

36. Park P, Garton HJ, Gala VC, Hoff JT, McGillicuddy JE. Adjacent segment disease after lumbar or lumbosacral fusion: review of the literature. Spine. 2004;29(17):1938-1944.

37. Yson SC, Sembrano JN, Sanders PC, Santos ERG, Ledonio CGT, Polly DWJ. Comparison of cranial facet joint violation rates between open and percutaneous pedicle screw placement using intraoperative 3-D CT (O-arm) computer navigation. Spine. 2013;38(4):E251-E258.

38. Tian W, Xu Y, Liu B, et al. Lumbar spine superior-level facet joint violations: percutaneous versus open pedicle screw insertion using intraoperative 3-dimensional computer-assisted navigation. Chin Med J (Engl). 2014;127(22):3852-3856.

39. Zhang Q, Xu YF, Tian W, et al. Comparison of superiorlevel facet joint violations between robot-assisted percutaneous pedicle screw placement and conventional open fluoroscopicguided pedicle screw placement. Orthop Surg. 2019;11(5):850856.

40. Le X, Tian W, Shi Z, et al. Robot-assisted versus fluoroscopy-assisted cortical bone trajectory screw instrumentation in lumbar spinal surgery: a matched-cohort comparison. World Neurosurg. 2018;120:e745-e751.

41. Le XF, Shi Z, Wang QL, Xu YF, Zhao JW, Tian W. Rate and risk factors of superior facet joint violation during cortical bone trajectory screw placement: a comparison of robot-assisted approach with a conventional technique. Orthop Surg. 2020;12(1):133-140.

42. Zhang H, Zhou D, Jiang Z. Analysis of accuracy of computer-assisted navigation in cervical pedicle screw installation. Orthop Surg. 2011;3(1):52-56.

43. Theologis AA, Burch S. Safety and efficacy of reconstruction of complex cervical spine pathology using pedicle screws inserted with stealth navigation and 3D imageguided (O-arm) technology. Spine. 2015;40(18):1397-1406.

44. Fan M, Liu Y, He D, et al. Improved accuracy of cervical spinal surgery with robot-assisted screw insertion: a prospective, randomized, controlled study. Spine. 2020;45(5):285-291.

45. Uehara M, Takahashi J, Ikegami S, Kuraishi S, Futatsugi T, Kato H. Screw perforation rates in 359 consecutive patients receiving computer-guided pedicle screw insertion along the cervical to lumbar spine. Eur Spine J. 2017;26(11):2858-2864.

46. Uehara M, Takahashi J, Ikegami S, et al. Optimal cervical screw insertion angle determined by means of computed tomography scans pre- and postoperatively. Spine J. 2017;17(2):190-195.

47. Shimokawa N, Takami T. Surgical safety of cervical pedicle screw placement with computer navigation system. Neurosurg Rev. 2017;40(2):251-258.

48. Yang YL, Zhou DS, He JL. Comparison of isocentric Carm 3-dimensional navigation and conventional fluoroscopy for $\mathrm{C} 1$ lateral mass and $\mathrm{C} 2$ pedicle screw placement for atlantoaxial instability. J Spinal Disord Tech. 2013;26(3):127-134.

49. Weng C, Tian W, Li ZY, et al. Surgical management of symptomatic os odontoideum with posterior screw fixation performed using the magerl and harms techniques with 
intraoperative 3-dimensional fluoroscopy-based navigation. Spine. 2012;37(21):1839-1846.

50. Tian W, Weng C, Li Q, et al. Occipital-C2 transarticular fixation for occipitocervical instability associated with occipitalization of the atlas in patients with klippel-feil syndrome, using intraoperative 3-dimensional navigation system. Spine. 2013;38(8):642-649.

51. Singh PK, Verma SK, Garg M, et al. Evaluation of correction of radiologic parameters (angulation and displacement) and accuracy of $\mathrm{C} 2$ pedicle screw placement in unstable Hangman's fracture with intraoperative computed tomography-based navigation. World Neurosurg. 2017;107:795-802.

52. Pisapia JM, Nayak NR, Salinas RD, et al. Navigated odontoid screw placement using the O-arm: technical note and case series. J Neurosurg Spine. 2017;26(1):10-18.

53. Jing L, Sun Z, Zhang P, Wang J, Wang G. Accuracy of screw placement and clinical outcomes after O-arm-navigated occipitocervical fusion. World Neurosurg. 2018;117:e653-e659.

54. Ray WZ, Ravindra VM, Schmidt MH, Dailey AT. Stereotactic navigation with the O-arm for placement of S-2 alar iliac screws in pelvic lumbar fixation. $J$ Neurosurg Spine. 2013;18(5):490-495.

55. Shillingford JN, Laratta JL, Park PJ, et al. Human versus robot: a propensity-matched analysis of the accuracy of free hand versus robotic guidance for placement of S2 alar-iliac (S2AI) screws. Spine. 2018;43(21):E1297-E1304.

56. Nottmeier EW, Fenton D. Three-dimensional imageguided placement of percutaneous pedicle screws without the use of biplanar fluoroscopy or Kirschner wires: technical note. Int J Med Robot Comput Assist Surg. 2010;6(4):483-488.

57. Laratta JL, Shillingford JN, Lombardi JM, et al. Accuracy of S2 alar-iliac screw placement under robotic guidance. Spine Deform. 2018;6(2):130-136.

58. Hyun SJ, Kim KJ, Jahng TA. S2 alar iliac screw placement under robotic guidance for adult spinal deformity patients: technical note. Eur Spine J. 2017;26(8):2198-2203.

59. Garrido BJ, Wood KE. Navigated placement of iliac bolts: description of a new technique. Spine J. 2011;11(4):331335 .

60. Santos ERG, Sembrano JN, Mueller B, Polly DW. Optimizing iliac screw fixation: a biomechanical study on screw length, trajectory, and diameter. $J$ Neurosurg Spine. 2011;14(2):219-225.

61. Balling H. Learning curve analysis of 3D-fluoroscopy image-guided pedicle screw insertions in lumbar single-level fusion procedures. Arch Orthop Trauma Surg. 2018;138(11):1501-1509.

62. Ryang YM, Villard J, Obermüller T, et al. Learning curve of 3D fluoroscopy image-guided pedicle screw placement in the thoracolumbar spine. Spine J. 2015;15(3):467-476.

63. Sasso RC, Garrido BJ. Computer-assisted spinal navigation versus serial radiography and operative time for posterior spinal fusion at L5-S1. J Spinal Disord Tech. 2007;20(2):118-122.

64. Qin H, Huang S, Xu L, et al. Radiation exposure and operation time in percutaneous endoscopic lumbar discectomy using fluoroscopy-based navigation system. World Neurosurg. 2019;127:e39-e48.

65. Khanna AR, Yanamadala V, Coumans JV. Effect of intraoperative navigation on operative time in 1-level lumbar fusion surgery. J Clin Neurosci. 2016;32:72-76.

66. Urakov TM, Chang KHK, Burks SS, Wang MY. Initial academic experience and learning curve with robotic spine instrumentation. Neurosurg Focus. 2017;42(5):E4. doi:10.3171/ 2017.2.FOCUS175

67. Schatlo B, Molliqaj G, Cuvinciuc V, Kotowski M, Schaller K, Tessitore E. Safety and accuracy of robot-assisted versus fluoroscopy-guided pedicle screw insertion for degenerative diseases of the lumbar spine: a matched cohort comparison. J Neurosurg Spine. 2014;20(6):636-643.

68. Hu X, Lieberman IH. What is the learning curve for robotic-assisted pedicle screw placement in spine surgery? Clin Orthop. 2014;472(6):1839-1844.

69. Xu YF, Le XF, Tian W, et al. Computer-assisted, minimally invasive transforaminal lumbar interbody fusion: one surgeon's learning curve: a STROBE-compliant article. Medicine (Baltimore). 2018;97(27):e11423. doi:10.1097/MD. 0000000000011423

70. Khanna R, McDevitt JL, Abecassis ZA, et al. An outcome and cost analysis comparing single-level minimally invasive transforaminal lumbar interbody fusion using intraoperative fluoroscopy versus computed tomography-guided navigation. World Neurosurg. 2016;94:255-260.

71. Park SM, Kim HJ, Lee SY, Chang BS, Lee CK, Yeom JS. Radiographic and clinical outcomes of robot-assisted posterior pedicle screw fixation: two-year results from a randomized controlled trial. Yonsei Med J. 2018;59(3):438-444.

72. Keric N, Doenitz C, Haj A, et al. Evaluation of robotguided minimally invasive implantation of 2067 pedicle screws. Neurosurg Focus. 2017;42(5):E11. doi:10.3171/2017.2. FOCUS16552

73. Tian W, Xu YF, Liu B, et al. Computer-assisted minimally invasive transforaminal lumbar interbody fusion may be better than open surgery for treating degenerative lumbar disease. Clin Spine Surg. 2017;30(6):237-242.

74. Xiao R, Miller JA, Sabharwal NC, et al. Clinical outcomes following spinal fusion using an intraoperative computed tomographic 3D imaging system. J Neurosurg Spine. 2017;26(5):628-637.

75. Kim HJ, Kang KT, Chun HJ, et al. Comparative study of 1-year clinical and radiological outcomes using robotassisted pedicle screw fixation and freehand technique in posterior lumbar interbody fusion: a prospective, randomized controlled trial. Int $J$ Med Robot Comput Assist Surg. 2018;14(4):e1917. doi:10.1002/rcs. 1917

76. Hyun SJ, Kim K-J, Jahng TA, Kim HJ. Minimally invasive robotic versus open fluoroscopic-guided spinal instrumented fusions: a randomized controlled trial. Spine. 2017;42(6):353-358.

77. Jiang B, Pennington Z, Azad T, et al. Robot-assisted versus freehand instrumentation in short-segment lumbar fusion: experience with real-time image-guided spinal robot. World Neurosurg. 2020;136:e635-e645.

78. Molliqaj G, Paun L, Nouri A, Girod PP, Schaller K, Tessitore E. Role of robotics in improving surgical outcome in spinal pathologies. World Neurosurg. 2020;140:664-673. doi:10. 1016/j.wneu. 2020.05

Disclosures and COl: Drs Chutkan and Araghi have disclosures that are outside the submitted work. For Dr Chutkan, this includes royalties from Globus Medical. For Dr Araghi, this includes being a prior shareholder in Globus 
Medical with royalties for sale of the robot and a nonfinancial disclosure regarding the development of fiducial positioning for navigation. Please see COI forms for further details. For the remaining authors, none were declared.

Corresponding Author: David H. Campbell, 1320 North 10th Street, Suite A; Phoenix, AZ
85006. Phone: (602) 839-3671; Email: dhcamp@ email.arizona.edu.

Published 26 October 2021

This manuscript is generously published free of charge by ISASS, the International Society for the Advancement of Spine Surgery. Copyright (C) 2021 ISASS. To see more or order reprints or permissions, see http://ijssurgery.com. 